\title{
Polyester or epoxy: assessing embedding product efficacy in paleohistological methods
}

\author{
Christian T Heck ${ }^{\text {Corresp., } 1}$, Gwyneth Volkmann ${ }^{1}$, Holly N Woodward ${ }^{1}$ \\ ${ }^{1}$ Department of Biomedical Sciences, Oklahoma State University Center for Health Sciences, Tulsa, Oklahoma, United States \\ Corresponding Author: Christian T Heck \\ Email address: ctheck@okstate.edu
}

Histological examination of bone microstructure provides insight into extant and extinct vertebrate physiology. Fossil specimens sampled for histological examination are typically first embedded in an inexpensive polyester resin and then cut into thin sections, mounted on slides, and polished for viewing. Modern undecalcified bone is chemically processed prior to embedding in plastic resin, sectioning, mounting, and polishing. Conversely, small fossil material and modern undecalcified bone are typically embedded in higher priced epoxy resin because these specimen types require final sections near or below $100 \mu \mathrm{m}$ thick. Anecdotal evidence suggests thin sections made of polyester resin embedded material polished thinner than $100 \mu \mathrm{m}$ increases likelihood of sample peeling, material loss, and is unsuitable for modern tissue and small fossil material. To test this assertion, a sample of modern bones and fossil bones, teeth, and scales were embedded in either polyester resin or epoxy resin. Embedded specimens were sectioned and mounted following standard published protocol. Thin sections were ground on a lapidary wheel using decreasing grit sizes until tissue microstructure was completely discernible when viewed under a polarizing light microscope. Additionally, eight prepared thin sections (four from polyester resin embedded specimens and four from epoxy resin embedded specimens) were continuously ground on a lapidary wheel using 600 grit carbide paper until peeling occurred or material integrity was lost. Slide thickness when peeling occurred was measured for comparing slide thickness when specimen integrity was lost between the two resin types. Final slide thickness ranged from $38 \mu \mathrm{m}$ to $247 \mu \mathrm{m}$ when tissue was identifiable using a polarizing microscope. Finished slide thickness varied between resin types despite similar tissue visibility. However, finished slide thickness appears more dependent on hard tissue composition than resin type. Additionally, we did not find a difference of slide thickness when material was lost between resin types. The results of this preliminary study suggest that polyester resins can be used for embedding undecalcified modern hard tissues and fossilized hard tissues without loss of tissue visibility or material integrity, at least in the short term.

Peer) reviewing PDF | (2020:07:51266:1:1:NEW 29 Oct 2020) 


\section{Polyester or epoxy: assessing embedding product} 2 efficacy in paleohistological methods.

3

4

5 6

7

9

10

11

12

13

14

15

16

17

18

19

20

21

22

23

24

25

26

27

28

29

30

31

32

33

34

35

36
Christian Thomas Heck ${ }^{1}$, Gwyneth Volkmann ${ }^{1}$, Holly N. Woodward ${ }^{1}$

${ }^{1}$ Department of Biomedical Sciences, Oklahoma State University Center for Health Sciences, Tulsa, Oklahoma, United States of America

Corresponding Author:

Christian Heck $^{1}$

$1111{\mathrm{~W} 17^{\text {th }}}^{\mathrm{St}}$, Tulsa, OK, 74136, USA

Email address: ctheck@okstate.edu 


\section{Abstract}

38 Histological examination of bone microstructure provides insight into extant and extinct vertebrate physiology. Fossil specimens sampled for histological examination are typically first embedded in an inexpensive polyester resin and then cut into thin sections, mounted on slides, and polished for viewing. Modern undecalcified bone is chemically processed prior to embedding in plastic resin, sectioning, mounting, and polishing. Conversely, small fossil material and modern undecalcified bone are typically embedded in higher priced epoxy resin because these specimen types require final sections near or below $100 \mu \mathrm{m}$ thick. Anecdotal evidence suggests thin sections made of polyester resin embedded material polished thinner than $100 \mu \mathrm{m}$ increases likelihood of sample peeling, material loss, and is unsuitable for modern tissue and small fossil material. To test this assertion, a sample of modern bones and fossil bones, teeth, and scales were embedded in either polyester resin or epoxy resin. Embedded specimens were sectioned and mounted following standard published protocol. Thin sections were ground on a lapidary wheel using decreasing grit sizes until tissue microstructure was completely discernible when viewed under a polarizing light microscope. Additionally, eight prepared thin sections (four from polyester resin embedded specimens and four from epoxy resin embedded specimens) were continuously ground on a lapidary wheel using 600 grit carbide paper until peeling occurred or material integrity was lost. Slide thickness when peeling occurred was measured for comparing slide thickness when specimen integrity was lost between the two resin types. Final slide thickness ranged from $38 \mu \mathrm{m}$ to $247 \mu \mathrm{m}$ when tissue was identifiable using a polarizing microscope. Finished slide thickness varied between resin types despite similar tissue visibility. However, finished slide thickness appears more dependent on hard tissue composition than resin type. Additionally, we did not find a difference of slide thickness when material was lost between resin types. The results of this preliminary study suggest that polyester resins can be used for embedding undecalcified modern hard tissues and fossilized hard tissues without loss of tissue visibility or material integrity, at least in the short term.

\section{Introduction}

Histological examination of bone allows interpretation of relative growth rates, absolute age, pathologies, and life history reconstructions of extinct and extant taxa (Marin-Moratalla et al. 2013; Cubo et al. 2015; Woodward et al. 2015; Calderon et al. 2019). Vertebrate paleontology studies increasingly incorporate osteohistology, or bone histotechniques, for these reasons, with large-sample studies becoming more common. The recognized utility of osteohistology necessitates investigating the cost-effectiveness of consumables involved to reduce expense, especially concerning large sample sizes.

Decalcification of modern hard tissues is necessary for specific staining protocol at the sacrifice of the mineral component (Skinner 2003). However, preparation of hard tissues without decalcification allows for investigation of mineralization patterns and direct comparisons with fossil specimens (Scarano, Orsini, \& Piattelli 2003; Skinner 2003; Straehl et al. 2013), as the unmineralized component of bone typically degrades prior to fossilization. Methodology for the 
77 preparation of undecalcified hard tissues, also simply termed 'calcified tissue', for histological

78

79

80

81

82

83

84

85

86

87

88

89

90

91

92

93

94

95

96

97

98

99

100

101

102

103

104

105

106

107

108

109

110

111

112

113

114

115

116 examination varies but generally includes stepwise tissue fixation, dehydration, and clearing prior to specimen embedding in resin, mounting the embedded specimen to a slide with glue, and thin section polishing (Fig. 1) (An et al. 2003, Schweitzer et al. 2007). Soft tissues in bone, e.g. oils, fats, and the collagen component of bone, are lost during the process of fossilization, thus, preparation of fossil hard tissues does not include the initial chemical treatments of modern hard tissues but still requires embedding in resin for stabilization, mounting, and polishing (Fig. 1) (Chinsamy and Raath 1992; Wilson 1994; Lamm 2013). Embedding, or investing, biological material for histological study was first introduced by Klebs (1869) using paraffin as the embedding medium (Sanderson et al 1988). Over the next century advancements in petrography and biological histology developed, and new methodologies for processing specimens emerged; however, protocol for histological processing of mineralized fossil material in publications was often absent or vague. Mineralized osteohistological studies have since utilized a variety of embedding mediums, with epoxy and polyester resins being common for extant bone and fossil bone respectively. However, choice of fossil and modern hard tissue embedding medium does not appear established on the basis of resin efficacy. Instead, resin selection seems to be personal preference or based off of published corporate technical notes (Ahmed and Vander Voort 2000; 2003). For instance, Chinsamy and Raath (1992) were the first to publish a detailed protocol for their preparation of fossil bone for histological study and utilized epoxy resin for their embedding medium. They state, “... any resin or other rigid, clear mounting medium which does not interfere with the structure or optical properties of the tissues could be used" (Chinsamy and Raath 1992, p. 40). Wilson (1994) also details methods used for preparing fossil bone for histological analysis and lists polyester resin as the preferred embedding medium for fossil bone. Lamm (2013) thoroughly describes the methodology developed at the Museum of the Rockies (Bozeman, MT, USA) for preparation and sectioning of fossil specimens for histological sampling. Lamm (2013) states that small fossils between one millimeter and one centimeter in length benefit from epoxy resin embedding due to the low viscosity of epoxy, which increases resin penetration, but that polyester resin is suitable for larger fossil material.

Resin choice is further compounded by price, with some epoxy resins costing up to $479 \%$ that of some polyester resins at the time of this publication. Such expenses can be prohibitive for underfunded researchers and institutions and necessitates determining cost effective alternatives. Here, we investigate the efficacy of polyester and epoxy embedding mediums (of different price points) commonly used in histological studies of fossil bone and modern undecalcified hard tissues to determine the variables requiring higher priced epoxy resins in the event that polyester and epoxy resins are similar in functionality.

\section{Materials \& Methods}

Fossil and modern hard tissues were chosen for sampling to test the efficacy of polyester and epoxy resins. The fossils are donated bones, teeth, and fish scales of unknown provenience. 
117 Fossil specimens include a turtle femur, two ornithischian dinosaur teeth, gar scale, crocodile 118 scute, and a rib and bone fragment of unknown taxa. Modern bones were either purchased raw 119 from a local grocery store (domestic chicken (Gallus gallus domesticus)) or collected as salvage 120 (nine-banded armadillo (Dasypus novemcinctus)). Salvage was collected under Oklahoma 121 collecting permits. The chicken humerus, tibia, and femur were sampled as well as both calcanea 122 from the nine-banded armadillo.

123 Fossil material was thoroughly scrubbed with an acetone-soaked brush to remove any

124 consolidants from the bone surface. Intensive exposure to acetone can have deleterious effects on 125 fossil bone, but we did not observe any damage to fossils from acetone washing. Specimens were 126 placed in small silicone containers and vacuum impregnated with either Silmar-41 two-part polyester resin, a commonly manufactured polyester resin, or Buehler Epothin (1 or 2, see Table 1) two-part epoxy resin (Buehler Ltd.). A variety of epoxy and polyester resins are utilized by osteohistological studies, but the two resins tested here are commonly used in paleohistological embedding (Lamm 2013). Buehler Epothin 1 became unavailable mid-way through the experiment and was replaced by two-part Buehler Epothin 2. We assume there is no major difference in efficacy between Epothin 1 and Epothin 2. Specimen processing then followed standard protocol outlined in Lamm (2013). All modern bones were processed prior to embedding using modified techniques from An et al. (2003) and Schweitzer et al. (2007) and outlined here. Modern material was soaked in warm water mixed with $1 \%$ Tergazyme Enzyme Detergent (Alconox Inc.) to degrade and to ease the removal of soft tissues from the bones. Specimens were air dried and remaining connective tissues and muscle remnants were removed via dissection. Bones were fixed in $10 \%$ formalin solution for 2-3 days. Specimens were then dehydrated in step-wise increasing concentrations of ethanol starting at $70 \% \mathrm{EtOH}$ for 48 hours, followed by $85 \% \mathrm{EtOH}$ for 48 hours, and finishing in $100 \%$ EtOH for 48 hours. Specimens were then cleared in Clear-Advantage Xylene Substitute (Polysciences Inc.) for 2-4 hours and set aside until dry (24-48 hours under a fume hood). Drying specimens after clearing introduces air back into the bone structure, but vacuum embedding replaces the reintroduced air with the embedding resin. Embedding procedure then proceeded as described above for fossil material (see Table 1 for embedding resin type used for each

147 specimen).

One to two thin sections were generated from each embedded specimen (Table 1). A Buehler Isomet 1000 saw (Buehler Ltd.), equipped with a 6" diamond cutoff blade, was used to cut thick wafers of approximately $2.5 \mathrm{~mm}$ from each embedded specimen block. One side of each wafer was ground on a Buehler Ecomet 4 lapidary grinder/polisher (Buehler Ltd.) using silicon carbide paper from 600 grit to 800 grit. Additionally, one side of the plastic slides was "frosted" using 600 grit silicon carbide paper on the Ecomet 4. Frosting of the wafer and plastic slide permits better adherence when glue is applied. Using 600 grit silicon carbide paper does not create scratches large enough to affect visibility of the finished section with microscope viewing. Wafers were placed under a fume hood for 24 hours to dry. After drying, wafers were mounted to frosted plastic slides with Starbond cyanoacrylate glue of medium viscocity to form a thin- 
157 section slide. Lamm (2013) recommends that polyester embedded specimens be mounted to

158

159

160

161

162

163

164

165

166

167

168

169

170

171

172

173

174

175

176

177

178

179

180

181

182

183

184

185

186

187

188

189

190

191

192

193

194

195

196

glass slides using two-part, two-ton epoxy, while epoxy embedded specimens be mounted to plastic slides using cyanoacrylate glue for better adherence. Recent processing of thin sections on glass with two-ton epoxy as the adhesive resulted in artifacts at the microscopic level. Although not visible in plane light, the artifacts appear as tiny birefringent square flakes in cross polarized light (Fig. 2). The presence of birefringent flakes is not isolated to any single brand of two-part epoxy, and are only present in the hardener component (HNW pers. obs.). However, the artifact can be eliminated by reheating the hardener component to $50^{\circ} \mathrm{C}$ (HNW pers. obs.). Here, we use plastic slides for all specimens because of the much lower cost of plastic slides relative to glass, and apply cyanoacrylate glue to (1) avoid potential visual complications caused by the use of two-ton epoxy and (2) continue following procedure outlined in Lamm (2013). Thin-sections (wafers mounted on slides) were set under a fume hood for 24 hours to cure and were then removed and allowed to cure for an additional 24 hours. Thin-sections were ground and polished using silicon carbide paper of decreasing grit sizes beginning at 320 grit and ending with 800 grit on a lapidary wheel until bone microstructure was visible and identifiable under a polarizing light microscope. Thin-section grinding on the lapidary wheel was controlled by hand and, thus, thin-sections were subjected to slight pressure variation during the grinding process. Slide holders can be used to eliminate pressure variation during lapidary wheel grinding, however, grinding was hand controlled in this study to better simulate low cost thin-section preparation techniques. Thin-sections were further polished by hand with $5 \mu \mathrm{m}$ and $1 \mu \mathrm{m}$ solutions.

Osteohistological studies often rely on qualitative descriptions such as that of bone tissue organization and vascular canal organization. Therefore, clarity of tissue organization and visibility between specimens embedded in the two resin types were qualitatively assessed by the authors. Thickness of finished slides was averaged for each specimen, but a targeted thickness was not set due to differences in transparency of tissue organizations. Differences in resin refractive index were not taken into account when assessing tissue visibility.

\section{Slide thickness and specimen peeling}

Two general kinds of damage can occur during grinding and polishing of hard tissues: (1) hard tissue material tearing, or popping, off the slide and (2) complete removal of specimen tissue due to excessive polishing. Lamm (2013) suggests epoxy resin performs better with material requiring extremely low thickness for tissue visibility whereas similar material embedded in polyester resin may succumb to the second type of damage during the grinding and polishing stage. Four specimens used in the study were chosen for further testing the ability of each resin to maintain specimen integrity when polished aggressively. The fossil rib and unknown bone fragment were carefully broken in half using a small hammer, and one half was embedded in Silmar-41 polyester resin and the other half embedded in either Buehler Epothin 1 or Epothin 2 epoxy resin (Table 1). Embedding protocol followed protocol previously stated. Testing each half in a different resin eliminated potential variation in tissue reaction based on mineral density, bone tissue organization, and/or vascular density. Similarly, one fossil tooth and the right nine-

Peer) reviewing PDF | (2020:07:51266:1:1:NEW 29 Oct 2020) 
197 banded armadillo calcaneum was embedded in Silmar-41 while a second fossil tooth and the left

198

199

200

201

202

203

204

205

206

207

208

209

210

211

212

213

214

215

216

217

218

219

220

221

222

223

224

225

226

227

228

229

230

231

232

233

234

235

236

nine-banded armadillo calcaneum was embedded in Buehler Epothin 2. Specimen processing and thin section preparation followed the previously stated protocol and the resultant thin section slides were polished on a lapidary wheel with 600 grit carbide paper until light could pass through the specimen. Thin sections were then polished further on the lapidary wheel using 800 grit carbide paper until specimen integrity was lost (damage type (1) or (2) as defined previously). Thickness of thin sections at moment of lost integrity was measured using a digital micrometer. Resultant thicknesses were compared between specimens embedded in each resin.

\section{Results}

We qualitatively assessed thin-sections produced from specimens embedded in the two resin types, Silmar-41 polyester resin and Buehler Epothin epoxy resins. Assessment included clarity of tissue organization and incurred thin section damage, as described previously. We found no appreciable difference in tissue clarity or visibility between specimens embedded in Buehler Epothin epoxy resin and specimens embedded in Silmar-41 polyester resin (Fig. 3). Additionally, we found no difference in thin-section quality between modern and fossil specimens regardless of resin type. None of the prepared thin-sections exhibited either type of damage prior to tissue organization being visible and identifiable under a polarized light microscope. Final thin section thicknesses ranged from $38 \mu \mathrm{m}$ to $247 \mu \mathrm{m}$ when tissue organization could be identified under a polarized light microscope; averaged thicknesses ranged from $46 \mu \mathrm{m}$ to $237 \mu \mathrm{m}$ (Table 2).

Finished, averaged thin-section thickness varied between resin types despite similar tissue visibility with specimens embedded in Buehler Epothin resins ranging from $46 \mu \mathrm{m}$ to $90 \mu \mathrm{m}$ and specimens embedded in Silmar-41 resin ranging from $56 \mu \mathrm{m}$ to $237 \mu \mathrm{m}$ (see Supp. 1 for individual slide thickness).

\section{Resin type and section damage}

We also did not find a difference between thin-section thickness at point of material damage, albeit with a small sample size. Table 2 lists the slide thickness at integrity loss for each specimen. Thickness at integrity loss was well beyond that in which bone microstructure was visible and identifiable in each specimen, and integrity loss resulted in damage type (1) (material tearing or popping off of the slide) (Fig. 4).

\section{Discussion}

Our results suggest that polyester resins can be used for embedding undecalcified modern bone and fossilized hard tissues without loss of tissue visibility or embedded material integrity. The finished section thickness did vary between Silmar-41 and Buehler Epothin embedded specimens. On average, epoxy resin embedded specimens had to be ground thinner than polyester embedded specimens to achieve similar levels of tissue visibility. However, finished section thickness appears more dependent on variation in hard tissue composition rather than resin type. For example, the fossil rib was divided into two parts and each part embedded in a 
237 different resin. The average finished section thickness of the polyester resin embedded rib part 238 was $56 \mu \mathrm{m}$ and the epoxy resin embedded rib part was $60 \mu \mathrm{m}$. Similar trends were observed in the 239 finished slide thicknesses of the divided unknown fossil bone fragment and the two fossil teeth.

240 The gar scale, composed of bone, dentine, and ganoin, was embedded in Silmar-41 resin and 241 finished section thickness was $226 \mu \mathrm{m}-247 \mu \mathrm{m}$, far thicker than any other finished thin section 242 (Supp. 1). Removal of the gar scale section thickness results reduces the polyester resin section 243 thickness range to $38 \mu \mathrm{m}-113 \mu \mathrm{m}$, closer in range to slides with epoxy resin embedded 244 specimens. Ideally, a future study will embed a fossil gar scale in epoxy resin for comparison of 245 similar specimen material compositions.

246 Resin type also did not appear to affect tissue visibility with the microscope or thickness at 247 material loss during polishing. Section thickness at moment of material integrity loss was similar 248 between resin types but varied among specimens, similar to results of finished slide thicknesses. This suggests that resin type has no appreciable effect on adherence or material loss at low section thicknesses.

251 Recently published methodologies for the preparation of undecalcified modern bones and small

252

253

254

255

256

257

258

259

260

261

262

263

264

265

266

267

268

269

270

271

272

273

274

275

276 fossil hard tissues show a preference for the use of epoxy resins as embedding media (Lamm 2013) rather than polyester-based media. In a brief survey of 134 research articles using histological sampling of either fossil bone or undecalcified modern bone (modern bone studies surveyed typically focused on non-primate tetrapods), we found polyester resins were preferably used in fossil studies ( $41 \%$ used a polyester resin, 32\% used an epoxy resin, $26 \%$ did not use polyester or epoxy or did not specify a resin type) and epoxy resins were preferred for modern undecalcified bone (59\% used an epoxy resin, $26 \%$ used a polyester resin, $15 \%$ did not use polyester or epoxy or did not specify). Epoxy resins were suggested to improve penetration and bonding of resin to the embedded hard tissue and to prevent material loss at low thin-section thickness. Polyester resins, on the other hand are recommended for larger fossil material (Wilson 1994; Lamm 2013), although several studies have utilized polyester resins for embedding modern undecalcified bone (e.g. Bourdon et al. 2009; Canoville, Schweitzer, \& Zanno 2019). Our study suggests that the less expensive polyester resins can be used interchangeably with the more expensive epoxy resins, decreasing the costs of histological preparation. However, this is a preliminary study and other variables may affect results including selection of mounting glue, hand pressure during polishing, humidity, room temperature, silicon carbide paper quality, and lab tech experience. In addition, our study focuses on specific resins used in protocol outlined in Lamm (2013) and excludes other commonly used resins (e.g. UV curing glue, Araldite, Technovit, etc.). Our study does not examine the long-term effects of resin types in terms of color changes or changes in brittleness of embedded specimens. Lamm (2013) notes changes in glue color (yellowing) and slide peeling have occurred in a few older specimens (histologically prepared over 24 years ago) in the Museum of the Rockies histology collection. A long-term study is necessary to ensure that resin type does not have a depreciable effect on stored embedded specimens. Lastly, modern specimens sampled were collected and salvaged for the purpose of this study and chemical processing was tightly controlled by the authors. In contrast, 
277 modern specimens in museum collections may have a complex and undocumented history of

278 chemical processing. Exposure to atypical chemicals during museum preparation and curation 279 may have deleterious effects on embedding efficacy or long-term integrity of embedded

280 specimens. The current study does not address any potential differences between 'freshly

281 collected' modern specimens and modern specimens that have been stored long-term in museum

282 collections, but future researchers should take into account any chemical used on specimens prior 283 to initiating histological processing.

284

285

286

287

288

289

290

291

292

293

294

295

296

297

298

299

300

301

302

303

304

305

306

307

308

309

310

311

312

313

314

315

316

\section{Conclusions}

Few studies have focused on product efficacy in paleohistological methods, potentially leading to unnecessary expenses. Epoxy resins are suggested to improve resin penetration, but incur a much larger financial cost relative to polyester resins. In this preliminary study, neither tissue quality under the microscope or integrity of specimen thin sections differed between polyester and epoxy resins. Institutions processing specimens for osteohistological sampling can alleviate some financial strain by utilizing polyester resins. However, long term storage may have negative effects on one resin type more so than another. The results of this study would benefit from an increased sample size and observation of resin embed deterioration over time.

\section{Acknowledgements}

The authors would like to thank Ellen-Thérèse Lamm and Museum of the Rockies for critical discussions, materials, and extensive training in osteohistology. Thank you to Andrew Lee for suggestions on how to remove the confetti artifact from two-ton epoxy.

\section{References}

Ahmed W and Vander Voort G. 2000. Petrographic examination methods. Tech-notes 3(5), Buehler Ltd.

Ahmed W and Vander Voort G. 2003. Specimen preparation of bones, tissues and other similar materials. Tech-notes 3(8), Buehler Ltd.

An Y, Moreira P, Kang Q, Gruber H. 2003. Principles of embedding and common protocols. In: An Y and Martin K, eds. Handbook of histology methods for bone and cartilage. New Jersey: Humana Press, 185 - 197.

Bourdon E, Castanet J, de Ricqlès A, Scofield P, Tennyson A, Lamrous H, Cubo J. 2009. Bone growth marks reveal protracted growth in New Zealand kiwi (Aves, Apterygidae). Biology Letters 5(5): 639 - 642 DOI 10.1098/rsbl.2009.0310. 
318 Calderon T, DeMiguel D, Arnold W, Stalder G, Köhler M. 2019. Calibration of life history traits 319 with epiphyseal closure, dental eruption and bone histology in captive and wild red deer. Journal 320 of Anatomy 235: $205-216$.

321

322 Canoville A, Schweitzer MH, Zanno LE. 2019. Systemic distribution of medullary bone in the 323 avian skeleton: ground trothing criteria for the identification of reproductive tissues in extinct 324 Avemetatarsalia. BMC Evolutionary Biology 19(1): 71 DOI 10.1186/s12862-019-1402-7.

325

326

327

328

329

330

331

332

333

334

335

336

337

338

339

340

341

342

343

344 Sanderson C, Emmanuel J, Emmanual J, Campbell P. 1988. A historical review of paraffin and

345

346

347

348

349

350

351

352

353

354

355

356

Chinsamy A and Raath M. 1992. Preparation of fossil bone for histological examination.

Palaeontologia Africans 29: 39 - 44.

Cubo J, Woodward H, Wolff E, Horner J. 2015. First reported case of biomechanically adaptive bone modeling in non-avian dinosaurs. PLOS One 10(7): e0131131 DOI

10.1371/journal.pone.0131131.

Klebs E. 1869. Die einschmelzungs, method, ein beitrag zur mikroskopischen technik. Arch mikr Anat 5: $164-166$.

Lamm ET. 2013. Preparation and sectioning of specimens. In: Padian K and Lamm ET, eds.

Bone histology of fossil tetrapods: advancing methods, analysis, and interpretation. California:

University of California Press, 55 - 160.

Marín-Moratalla N, Jordana X, Köhler M. 2013. Bone histology as an approach to providing data on certain key life history traits in mammals: implications for conservative biology. Mammalian Biology 78: $422-429$.

its development as an embedding medium. Journal of Histotechnology 11: $61-63$.

Scarano A, Orsini G, Piattelli A. 2003. Infiltration techniques and results in different types of resin. In: An Y and Martin K, eds. Handbook of histology methods for bone and cartilage. New Jersey: Humana Press, 199 - 206.

Schweitzer MH, Elsey RM, Dacke CG, Horner JR, Lamm E.-T. 2007. Do egg-laying crocodilian (Alligator mississippiensis) archosaurs form medullary bone? Bone 40: 1152-1158.

Skinner R. 2003. Decalcification of bone tissue. In: An Y and Martin K, eds. Handbook of histology methods for bone and cartilage. New Jersey: Humana Press, 167 - 184.

PeerJ reviewing PDF | (2020:07:51266:1:1:NEW 29 Oct 2020) 
357 Straehl F, Scheyer T, Forasiepi A, MacPhee RD, Sánchez-Villagra MR. Evolutionary patterns of 358 bone histology and bone compactness in xenarthran mammal long bones. PLOS One 8(7):

359 e69275 DOI 10.1371/journal.pone.0069275

360

361 Wilson J. 1994. Histological techniques. In: Leiggi P and May P. Vertebrate paleontological 362 techniques, Vol. One. New York: Cambridge University Press, 205 - 234.

363

364 Woodward H, Fowler E, Farlow J, Horner J. 2015. Maiasaura, a model organism for extinct 365 vertebrate population biology: a large sample statistical assessment of growth dynamics and 366 survivorship. Paleontology 41(4): 503 - 527. DOI 10.1017/pab.2015.19. 


\section{Table $\mathbf{1}$ (on next page)}

Material histologically sampled using either polyester resin or epoxy resin as the embedding medium.

Specimens sampled for this study included modern and fossil hard tissues. * - indicates material used to compare specimen integrity during thin section grinding and polishing. 
1

\begin{tabular}{|c|c|c|c|c|}
\hline Resin Type & Specimen Age & Specimen & Element & No. of Sections \\
\hline \multirow{10}{*}{$\begin{array}{l}\text { Polyester Resin } \\
\text { (Silmar-41) }\end{array}$} & Modern & Domestic Chicken & Humerus & 2 \\
\hline & & & Femur & 2 \\
\hline & & & Tibia & 2 \\
\hline & & Nine-banded Armadillo & Right Calcaneum* & 2 \\
\hline & Fossil & Indet. Turtle & Femur* & 2 \\
\hline & & Gar & Scale & 2 \\
\hline & & Indet. Crocodile & Scute & 2 \\
\hline & & Indet. Ornithopod & Tooth* & 2 \\
\hline & & Unknown & Rib & 2 \\
\hline & & Unknown & Fragment* & 1 \\
\hline Epoxy Resin & Modern & Nine-banded Armadillo & Left Calcaneum* & 2 \\
\hline \multirow[t]{3}{*}{ (Epothin-1) } & Fossil & Indet. Turtle & Femur* & 1 \\
\hline & & Unknown & Rib & 1 \\
\hline & & Indet. Ceratopsian & Tooth* & 2 \\
\hline (Epothin-2) & & Unknown & Fragment* & 1 \\
\hline
\end{tabular}




\section{Table 2 (on next page)}

Slide thickness of each finished thin section and thickness at material loss.

Thin sections were defined as finished when tissue organization was visible and identifiable using a polarizing light microscope. Select thin sections were further ground on a lapidary wheel until material integrity was lost and the thickness of the specimen when material damage incurred was measured. 
1

\begin{tabular}{cllcc} 
Resin Type & Specimen & Element & $\begin{array}{c}\text { Avg. Finished } \\
\text { Slide } \\
\text { Thickness } \\
(\mu \mathrm{m})\end{array}$ & $\begin{array}{c}\text { Slide Thickness } \\
\text { at Loss }(\mu \mathrm{m})\end{array}$ \\
\hline $\begin{array}{c}\text { Polyester Resin } \\
\text { (Silmar-41) }\end{array}$ & Domestic Chicken & Right Humerus & 72 & - \\
& Nine-banded & Right Femur & 61 & - \\
& Armadillo & Right Tibia & 100 & - \\
\cline { 2 - 5 } & Indet. Turtle & Femur & 66 & 60 \\
& Gar & Scale & 64 & - \\
& Indet. Crocodile & Scute & 237 & - \\
& Indet. Ornithopod & Tooth & 70 & - \\
& Unknown & Rib & 66 & 67 \\
& Unknown & Fragment & 56 & 71 \\
& Nine-banded & Left Calcaneum & 78 & 44 \\
\hline Epoxy Resin & Armadillo & & 80 & - \\
\cline { 2 - 5 } (Epothin-1) & Indet. Turtle & Femur & 46 & 20 \\
& Unknown & Rib & 60 & 81
\end{tabular}


Figure 1

Simplified protocol for osteohistological protocol.

In standard protocol, processing of modern specimens (top) requires chemical processing prior to embedding in epoxy resin. Fossil samples do not require chemical processing, but consolidants must be removed prior to embedding in polyester resin.
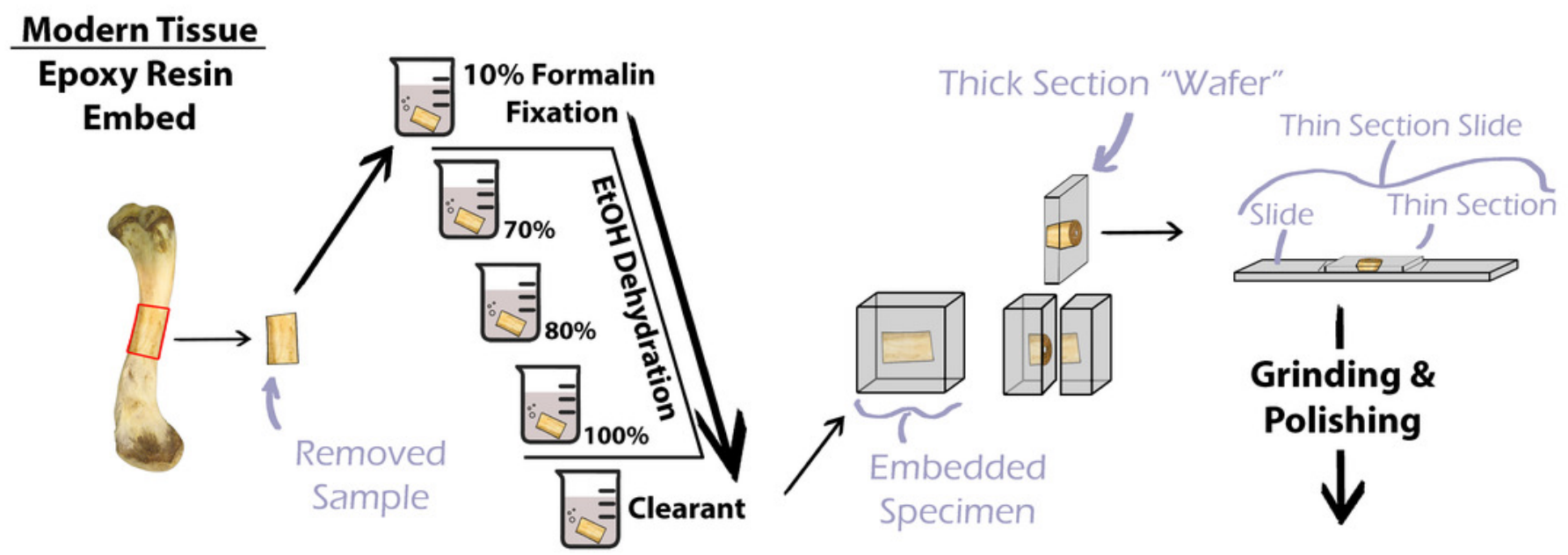

\section{Fossil Specimen}

Polyester Resin

Embed

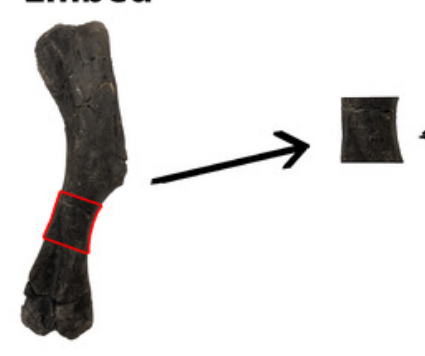

Consolidant

Removal

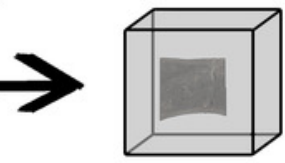

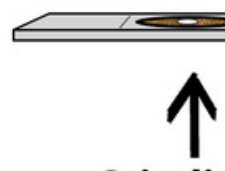

Grinding \&

Polishing

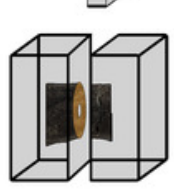




\section{Figure 2}

Visual obstructions in the mounting medium 2-ton epoxy resin.

2-ton epoxy resin is used as a mounting medium for polyester resin embedded specimens to glass slides. (A) A drop of 2-ton epoxy resin imaged showing 'confetti' visual obstructions. (B) "Confetti" obstructing tissue visibility in a Maiasaura tibia cross-section. Both images taken with a camera mounted to a polarizing light microscope with a 1/4 lambda wave plate.

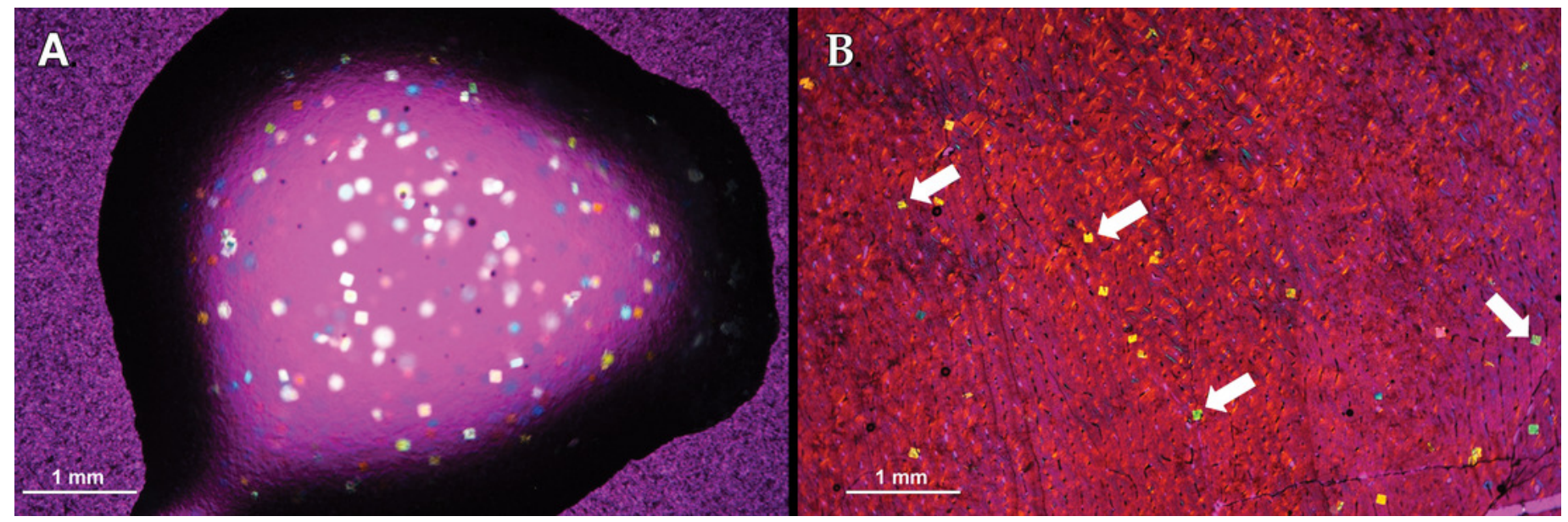




\section{Figure 3}

Tissue clarity between polyester and epoxy resin embedded specimens.

Separate parts of a fossil rib of an indeterminate taxa were embedded in (A) polyester resin and (B) epoxy resin and the finished sections imaged under linear light with a polarizing light microscope. Tissue clarity, as qualitatively assessed by the authors when viewed with a polarizing light microscope, did not appear to be affected by resin type. (C) Transverse section of the calcaneum of Dasypus novemcinctus embedded in polyester resin and (D) transverse section of Gallus gallus domesticus humerus embedded in polyester resin. Tissue clarity in modern tissue was not affected by the use of polyester resin. 


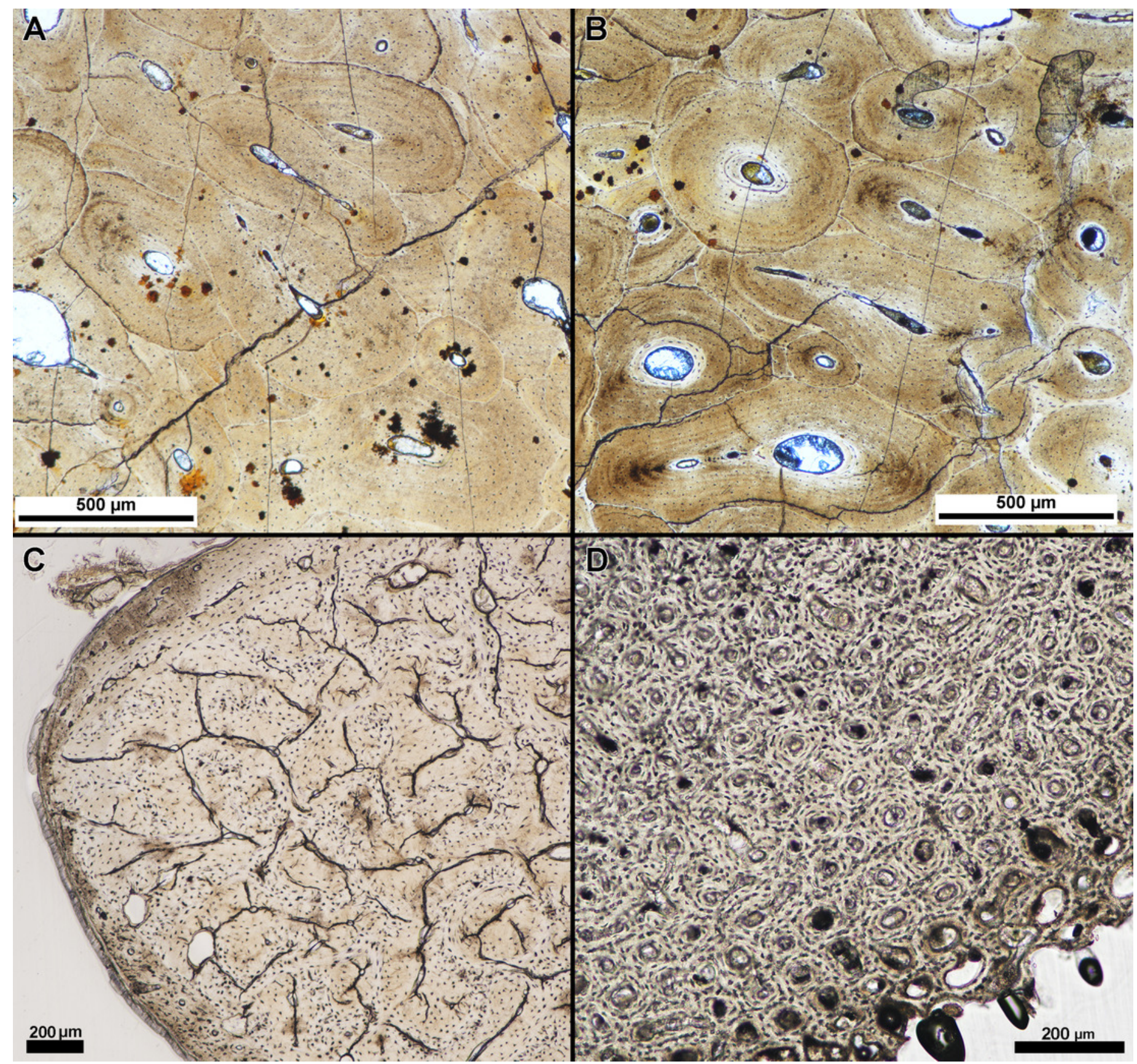


Figure 4

Example of specimen damage incurred during grinding and polishing.

(A) Thin section of fossil turtle femur embedded in polyester resin was ground on a lapidary wheel until specimen integrity was lost. (B) Inset of (A) showing region of specimen (red shade) that ripped off of the slide when ground too thin. Image taken under linear polarized light.

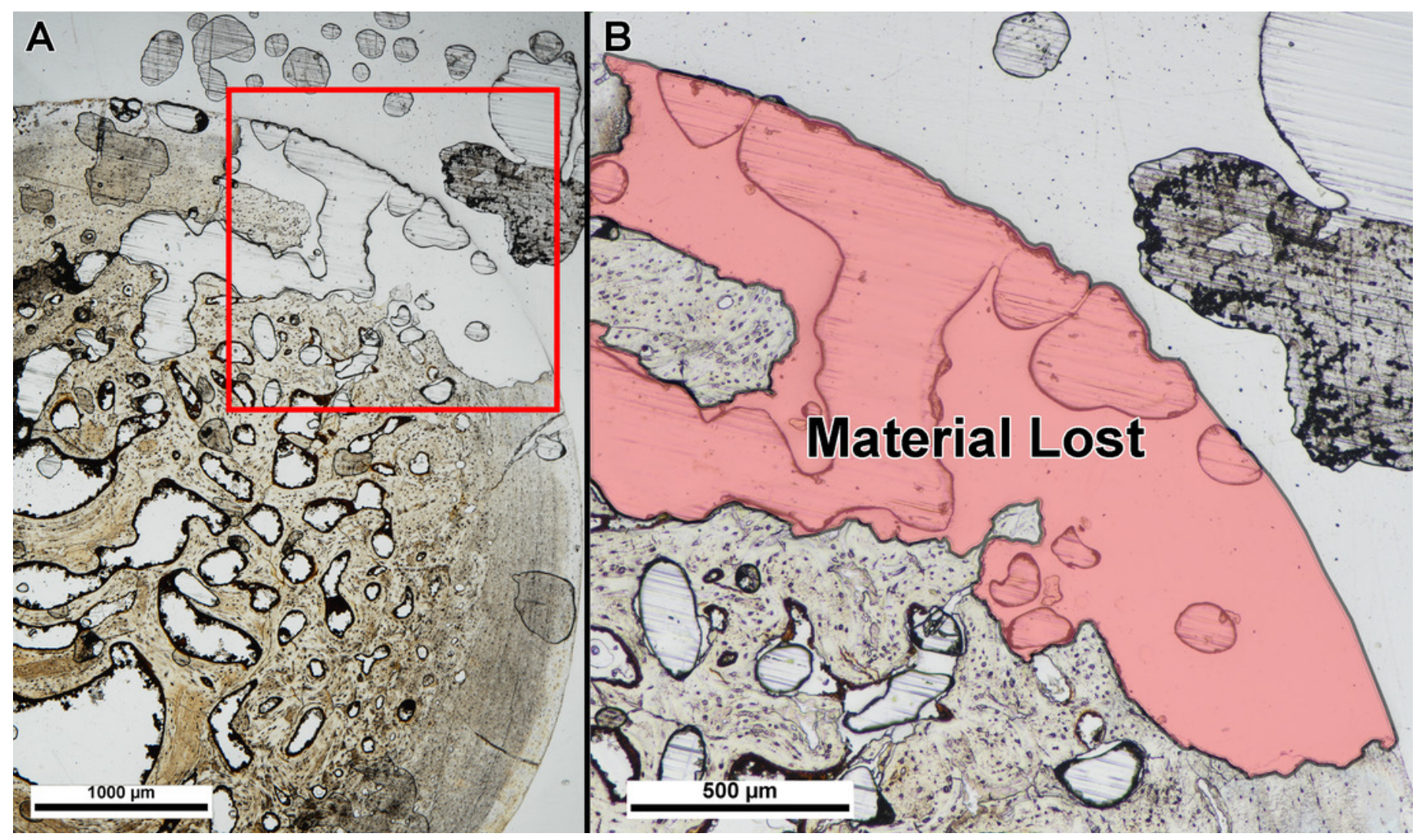

